\title{
Makna Seksualitas dalam Naskah Sastra Pesantren
}

\author{
Muhammad Abdullah \\ Fakultas Ilmu Budaya, Universitas Diponegoro \\ abdullahabah47@gmail.com.
}

\begin{abstract}
The study of "Uqudullujjain Fi Huqquq Azzaujain" text shows that there is strong gender bias and sexual in the discourse of pesantren literature. It can be seen, among others, from the domestication of women in household. For example, women are suggested to work at home (doing things around the well, bedroom, and kitchen). Women are supposed to be housewives, and so they are prohibited to work outside their home, and they are given limited access to go outside. However, time has changed gender perspective. Nowadays there has been development of new advances occurring among pesantren leaders. For example, there are many Muslim women who work in economic or politic sectors as mass leaders, regents, mayors and district or village heads. This certainly shows interesting opportunities for women to be equal to men. Therefore, in the future, women will be able to be more independent, strong, and even they can obtain good achievements.
\end{abstract}

Keywords: gender bias, sexjuality, pesantren literature, equal

\section{Intisari}

Penelitian terhadap teks Uqudullujain ini mengungkapkan tertang wacana bias gender dan wacana seksualitas dalam tradisi pesantren. Penelitian inki menggunakan metode dan pendekatan filologi. Metode ini untuk mendeskripsi dan mengidentifikasi naskah-naskah pesantren. Dalam kajian isi teks penelitian ini menggunakan metode tematik, yaitu metode yang mengkaji dan menelaah isi teks sesuai dengan tema pokok yang ada dalam teks. Pada bagian belakang buku itu dipaparkan bagaimana membangun hubungan seks yang maksimal, memberikan resep dan ramuan jamu Arab. Sebagai contoh, dijelaskan dalam buku itu bahwa dengan ramuan minyak unta, madu, jahe, perasan bawang, dan puluhan kuning telor, seorang "raja" Arab dapat memerawani delapan puluh gadis dalam semalam, tanpa orgasme.

Kata kunci: bias gender, seksualitas, sastra pesantren, kesetaraan

\section{Pendahuluan}

Pondok pesantren sebagai basis pendidikan Islam, di samping memiliki tradisi lisan yang kuat, juga memiliki tradisi intelektual yang terungkap dalam berbagai karya tertulis. Di 
antaranya berupa karya Sastra Pesantren, yaitu kumpulan karya sastra kitab (sastra keagaman) dan sastra syi'ir, dan sastra lisan pesantren. Menurut Braginsky (1993 : 3; Hadi WM, 2004: 49), sastra keagamaan itu adalah kitab-kitab yang berisi ajaran hukumhukum formal agama (syari'at), teologi, tasawuf, dan metafisika Islam. Dalam khazanah sastra pesantren banyak naskah keagamaan yang berisi ajaran Islam yang kurang mendapat perhatian dari kalangan peneliti. Karya-karya sastra tertulis pesantren menurut para ahli telah memberikan kontribusi yang berharga bagi penyebaran dan perkembangan Islam di Nusantara. Bahkan menurut Soebardi (1976: 3), karya-karya pesantren itulah yang paling menentukan watak keislaman dari kerajaan-kerajaan Islam dan kemajuan Islam di Indonesia dalam kurun waktu berabad-abad.

Dalam sejarah intelektual Islam Indonesia, pesantren merupakan basis pengajaran Islam tradisional yang berakar dari kitab-kitab Islam klasik (Abdullah, 1995: 40). Dari pesantren itulah dapat diketahui sistem pengajaran yang didasarkan pada sumber-sumber tertulis berupa naskah-naskah klasik maupun kitab klasik terbitan Timur Tengah yang merupakan karya ulama salaf. Yaitu ulama-ulama ahli fiqih, hadis, tafsir, ilmu kalam dan tasawuf yang hidup antara abad ketujuh sampai dengan abad ketiga belas Masehi (Dhofier, 1982:8). Kitab-kitab jenis inilah yang dalam sastra Melayu dan tradisi pesantren dikenal sebagai sastra kitab, atau secara khas disebut kitab kuning (Wahid, 1989 : 31 ; Liaw Yock Fang, 1993 : 41). Kitab-kitab kuning yang menurut van Bruinessen merupakan tradisi agung (great tradition) di Nusantara, dipakai sebagai alat transmisi ajaran Islam tradisional di Jawa pada abad 18-19 (Bruinessen, 1999: 17).

Melalui karya pesantren inilah tradisi pemikiran dan intelektual Islam diwariskan secara turun temurun, dari satu generasi ke generasi berikutnya. Dari segmen inilah sesungguhnya jaringan intelektual Islam Indonesia tumbuh dan berkembang. Hal ini terutama terjadi pada era ulama besar seperti Syeikh Abdus Samad Al-Palembani, Syeikh Abdur Rauf As-Singkili, Syeikh Yusuf Al-Makassari, Hamzah Fansuri, Syamsuddin AsSamatrani, Nuruddin Ar-Raniri, Muhammad Arsyad Al-Banjari, dan lain-lainnya sampai akhirnya muncul generasi Imam Nawawi Al-Bantani, Kyai Ihsan Jampes, Kyai Saleh Darat (Shalih bin Umar Al-Samarani, w.1321/1903), sekitar abad 17-19 M. Pasca abad 
19 muncul nama-nama penulis kitab dan sastra pesantren, seperti KH Mahfudz dari Tremas yang hidup dan mengajar di Makkah sekitar tahun 1900-an; ulama lain adalah KH Ihsan bin Muhammad Dahlan dari Jampes Kediri yang menulis kitab Siraj AlThalibin. Selain itu ada Ulama Jawa yang sangat produktif adalah KH Bisri Mustofa (ayah dari KH Mustofa Bisri) dari Rembang. Dia menulis lebih dari dua puluh karya pesantren. Penulis lain dari ulama Jawa adalah KH Muslikh dari Mranggen (Muslikh bin Abd Al-Rahman Al-Maraqi, w. 1981) yang menulis berbagai risalah tentang tarekat Qadiriyah waNaqsabandiyah, dan Ahmad 'Abdul hamid Al-Qandali dari Kendal (lihat, Azra, 1994: 36; Bruinessen, 1999: 19-20; Daudy, 1983: 35; Baried dalam Drewes, 1990: vii; Thohari, 1991).

Tradisi intelektual Islam inilah yang terungkap melalui tradisi tulis dalam bentuk pendidikan, pemikiran dan budaya Islam. Itulah sebabnya jejak-jejak intelektual Islam itu justru muncul dalam bentuk naskah-naskah klasik keagamaan yang berisi berbagai pengajaran Islam, seperti tauhid, tafsir, ahlak, fiqih, dan pengajaran tasawuf, atau disebut juga sastra tasawuf (Liaw Yock Fang, 1993: 41-42). Namun tampaknya, di Indonesia tradisi keberaksaraan ini justru mengalami penurunan setelah kejayaan pemikiran Imam Nawawi Al-Bantani dari Banten yang karya-karyanya banyak dipakai di kawasan India dan negara-negara Timur Tengah (Hasan, 1990: 21). Di antara faktor yang mempengaruhi merosotnya tradisi penulisan di kalangan ulama Indonesia waktu itu hingga belakangan ini adalah (1) semakin kuatnya pengaruh budaya oral (oral tradition) yang melembaga dalam tradisi masyarakat Islam, sehingga para kyai atau ulama lebih suka mengaktualisasikan ilmunya melalui pengajian dan ceramah-ceramah; lemahnya etos keberaksaraan ${ }^{1}$ dalam tradisi pesantren di Indonesia, terutama disebabkan kebiasaan melakukan pengajaran lisan, baik berupa ceramah agama, atau penyampaian pengajaran kitab kuning di pesantren secara manqul dan sorogan, ${ }^{2}$ (3) dan terjadinya pergeseran orientasi masyarakat dari dunia keilmuan ke lapangan lain, seperti misalnya

\footnotetext{
1 Pinjam istilah A.Teeuw (1994) dalam Indonesia : Antara Kelisanan dan Keberaksaraan. Jakarta : Gramedia. Keberaksaraan dimaksudkan sebagai kemampuan menulis teks secara ilmiah.

${ }^{2}$ Sistem pengajaran manqul adalah model penyampaian pendidikan dengan metode penurunan teks secara lisan, tanpa perubahan sedikit pun dari guru (kyai) terdahulu kepada santrinya. Sedang sorogan atau talaqqi adalah metode pengajaran pesantren dengan cara santri menghadap kyai satu per satu (face to face) untuk menerima pengajaran lisan dari kyainya, sesuai kitab yang diajarkannya (Dhofier, 1982: 12).
} 
dunia politik dan ekonomi (Dhofier, 1982: 9; Thohari, 1991; Abdullah, 1995: 23; Bruinessen, 1999: 25-26).

Dalam perkembangannya, sastra pesisir terbagi ke dalam tradisi tulis dan tradisi lisan. Di antara tradisi tulis dalam sastra pesantren itu meliputi naskah-naskah tentang (1) Naskah syi'ir-syi'ir pesantren, (2) puisi Al-Barzanji, (4) puisi Burdah (5) nadhoman, dan lain-lain. Syi'ir pesantren biasanya dibuat berdasarkan sumber tertentu, misalnya bersumber dari kitab suci Al-Quran, Al-hadis, Burdah, Syaraful Anam, dan lain lain yang kemudian diramu dengan imajinasi penulisnya. Misalnya Syi'ir Abu Nawas yang berisi tentang doa Abu Nawas kepada Allah SWT untk mendapatkan keridhaan-Nya. Karya Syi'ir Tomba Ati, Syi’ir Erang-erang Sekar Panjang karya Kyai Siradj Payaman Magelang yang menceritakan keadaan siksa neraka dan kenikmatan di surga, dan lainlain.

Sedangkan karya sastra pesisir yang dapat digolongkan sebagai karya tradisi lisan dan folklor adalah (1) Hagiografi, yaitu cerita orang-orang suci, seperti cerita Syekh Siti Jenar (Pekalongan), Syek Mutamakin (Pati), Syekh Ahmad Rifa'i (Batang), Sunan Katong (Kaliwungu Kendal), Sunan Kalijaga (Demak), Syekh Ja'far Shodiq (Kudus) dan lain-lain, (2) legenda daerah (asal usul nama kota, nama-nama tempat), (3) mitos-mitos tempat wisata ziarah, (4) Tradisi wirid dan hizib dalam radisi pesantren, seperti Pencak silat Asma'ul Husna, Hizb lathif, Hizb Nashar yang merupakan bagian tradisi lisan pesantren.

\section{Manuskripta Pesantren}

Meskipun sudah banyak dilakukan penelitian terhadap naskah-naskah klasik Nusantara, namun sampai saat ini publikasi mengenai hal itu masih sangat terbatas jumlahnya. Hal ini karena hasil-hasil penelitian itu hanya dinikmati oleh kalangan tertentu, terutama di kalangan akademisi yang langsung berhubungan dengan disiplin ilmu sastra, linguistik, filologi atau sejarah. Dengan demikian penelitian naskah-naskah itu belum mampu merambah masuk ke dalam ranah atau disiplin ilmu yang lebih luas 
yang bersifat lintas disiplin (interdisipliner), seperti antropologi, sosial-politik, psikologi, agama, kesehatan, teknik dan lainnya. ${ }^{3}$

Oleh karena itu, untuk memberikan sumbangan pemikiran kepada para peneliti, pemerhati, dan pembaca secara lebih luas, maka sangat diperlukan kajian-kajian ilmiah terhadap naskah-naskah klasik pesantren peninggalan masyarakat masa lampau. Hal ini penting dilakukan mengingat naskah-naskah itu banyak mengandung pelajaran berharga bagi generasai masa kini. Sebagai peninggalan masa lampau, naskah-naskah itu menyimpan berbagai nilai kehidupan, yang dapat berguna untuk kehidupan masyarakat masa kini, seperti ajaran agama, sejarah, hukum, adat istiadat, filsafat, sastra, politik, bahasa, mantra, obat-obatan dsb. (Soeratno, 1996: 4).

Naskah-naskah klasik Nusantara itu sampai saat ini masih banyak tersimpan di berbagai tempat seperti perpustakaan, museum, baik di dalam maupun di luar negeri. Di antara khazanah naskah yang menyimpan hasil kebudayaan masa lalu yang mengagumkan itu adalah naskah-naskah Melayu klasik. Naskah-naskah Melayu klasik yang berisi berbagai nilai spiritual Islam itu masih cukup banyak jumlahnya. Hussein (1974:12) misalnya, pernah menyatakan bahwa naskah-naskah itu belum ditangani secara optimal. Bahkan Henri Chambert-Loir dalam Archipel 20 (1980: 45) menyebutkan bahwa terdapat lebih dari empat ribu naskah Melayu yang belum diteliti orang secara serius. Akibatnya banyak di antara naskah-naskah itu yang tersimpan di perpustakaanperpustakaan di berbagai negara yang belum dijamah peneliti (Robson, 1978: 2-3). Bahkan masih banyak pula naskah Nusantara yang terdapat di berbagai lembaga masyarakat, seperti yang masih tersimpan di pondok-pondok pesantren tradisional di Indonesia belum ditangani dengan baik.

Meskipun penelitian sastra-sastra Nusantara sudah banyak dilakukan orang, namun tidak demikian halnya dengan karya sastra pesantren, sejenis Syi'ir. Selama ini jenis sastra Syi' ir kurang diminati para peneliti. Hal ini terbukti dari berbagai penelitian

${ }^{3}$ Soeratno, Siti Chamamah. 2003.Filologi Sebagai Pengungkap Orisinalitas dan Transformasi Produk Budaya. Pidato Pembukaan Kuliah Program Pascasarjana Universitas Gadjah Mada Tahun akademik 2003/2004, 1 September 2003. 
sastra Jawa yang dilakukan para ahli seperti Poerbatjaraka dan Tardjan Hadidjaja (1952), Padmosoekotjo (1960), Ras (1985), Zoetmulder (1983), Subalidinata (1996), Nielsmulder (1986), tidak membicarakan tentang sastra syi'ir. Anehnya lagi, dalam berbagai katalogus naskah Jawa seperti Katalogus Pigeaud (1973), Katalog Girardet (1983), dan Katalog Behrend (1993) tidak ditemukan catatan tentang syi'ir (Jawa : Singir). Penelitian akademis tentrang syi'ir pun masih bisa dihitung dengan jari tangan. Karya-karya itu misalnya skripsi S-1 (Muayyanah, 1996; Saifuddin, 1997), dan sebuah tesis S-2 (Muzakka, 1999).

Hasil inventarisasi yang dilakukan oleh Museum Pusat Jakarta tentang karya sastra syi'ir hanya meng-cover empat buah syi'ir (Soewignjo dan Wirawangsa, 1920 :318). Meskipun demikian, sampai saat ini tampaknya belum ada usaha penelitian lanjutan yang merekan sejumlah naskah syi'ir di kalangan pesantren. Kurang tahu persis, mengapa penelitian tentang syi'ir masih rendah peminatnya. Barangkali karena kurangnya sosialisasi dan publikasi karya syi'ir secara umum. Untuk menjawab persoalan ini, maka sangat dirasa penting penyunyingan dan penerbitan naskah syi'ir untuk konsumsi masyarakat akademis dan masyarakat pada umumnya.

Dalam perkembangan sejarahnya, tradisi filologi pesantren di Nusantara sebetulnya muncul dan berkembang belum lama. Hal ini karena para sarjana sastra yang brminat dan mau menggeluti penelitian sastra pesantren boleh dikatakan tidak banyak. Penelitian awal, misalnya, boleh sekedar menyebut beberapa nama dan hasil penelitiannya. Di antaranya para peneliti dari IAIN Walisongo Semarang, seperti Muchoyyar dalam penelitiannya terhadap naskah tafsir pesantren klasik karya Kyai Saleh Darat Semarang, Abdul Djamil (2002), dalam penelitianya terhadap naskah-naskah Kyai Rifa'i Pekalongan, Muslich Sobir (2008), dan Anasom (2006), dalam penelitianya terhadap naskah-naskah keagamaan dan naskah syi'ir pesantren. Para peneliti lain yang mengadakan penelitian terhadap naskah-naskah sastra pesantren, misalnya dapat disebut peneliti dari UNDIP Semarang, Muhammad Abdullah (2006), dan Muh. Muzakka (2001) dalam penelitiannya terhadap sastra syi 'ir pesantren. Di samping penelitiannya terhadap naskah sastra al-Barzanji, Manakib Syekh Abdul Qadir Al-Jailani, tradisi wirid, hizib dan 
wifik dalam sastra pesantren, Muhammad Abdullah, juga meneliti masalah teologi dan sufisme dalam sastra pesantren. Buku hasil penelitiannya di antaranya Dekonstruksi Sastra Pesantren (2006), Khazanah Sastra Pesisir (2010), dan beberapa hasil penelitian yang belum diterbitkan. Peneliti lain yang cukup mendapat resistensi tinggi dari kalangan ulama adalah ketika penulis mengadakan penelitian terhadap kitab "uqudulujain. Ada asumsi bahwa kitab tersebut isinya sedikit banyak mengindikasikan ketimpangan gender. Kitab ini juga dianggap mempengaruhi "domistikasi” wanita Islam dalam masyarakat di lingkungan pesantren. Karena itu dalam dunia pesantren, dominasi kekuasaan masih terasa kuat dimiliki kaum santri laki-laki, sementara kaum perempuan masih dianggap inferior dalam masyarakat. Meskipun demikian, kitab 'Uqudullujain dan Kitab Qurrotul 'Uyun telah memberikan pendidikan seksual yang berharga bagi civitas akademika pesantren.

\section{Makna Seksualitas dalam Sastra Pesantren}

Dominasi budaya patriarkal dalam wacana perempuan di Indonesia telah lama dirasakan dampaknya dalam masyarakat. Dominasi itu secara luas telah masuk dalam semua lini kehidupan, baik dalam dunia pendidikan, ekonomi, politik, arsitektur, ${ }^{4}$ bahkan dalam teks-teks keagamaan. Di pihak lain dominasi patriarkal itu juga telah memicu lahirnya diskriminasi dan ketimpangan gender, yakni peran dan kedudukan perempuan dalam keluarga, masyarakat dan negara. Dalam kondisi seperti ini maka perempuan tak lebih hanya sebagai subordinasi laki-laki.

Oleh karena itu, sangat mudah dimengerti bahwa di bawah bayang-bayang sistem patriarki, perempuan memang kadang tidak lebih dari sekedar pendamping laki-laki, yang kadang "harus mengalah". Merasakan limbo kesejarahan ini, maka seorang Nawal El Sadawi dalam bukunya Perempuan di Titik Nol (1993) berusaha memberontak kemapanan dunia laki-laki. Bahkan yang paling menyedihkan ialah kasus kegelisahan yang menimpa seorang aktivis feminisme, Virginia Woolf. Ia adalah sastrawan besar

\footnotetext{
${ }^{4}$ Pada awalnya belum terbuka kasus ketimpangan gender dalam bidang arsitektur. Namun ternyata dampak pembangunan pasar Bringharjo Yogyakarta membawa dampak ketidakadilan gender itu. Salah satu isunya ialah karena tempat penjualan bumbon dan uba rampe perempuan, justru ditempatkan di lantai atas, lantai III, dan ini ternyata menyulitkan pekerja wanita (baca: buruh wanita) yang juga mempertinggi penyakit farises.
} 
kelahiran Inggris yang hidup pada awal abad ke-20. Sebagaimana Simone de Beauvoir, Woolf cukup gigih memperjuangkan hak-hak asasi perempuan dan menentang dominasi pria. Tragisnya, ia memutuskan untuk bunuh diri, menerjunkan diri ke sungai Osse. Suatu pilihan eksistensial yang amat dramatis. ${ }^{5}$

Dalam prakteknya di masyarakat modern dewasa ini, hasrat seksual seseorang seringkali tidak dikemas dan disalurkan sesuai aturan atau norma-norma yang berlaku, baik norma susila, adat maupun norma agama. Karena itu, yang muncul dan membudaya adalah pelampiasan seks yang mengedepankan nafsu birahi, nafsu ananiyah semata, bahkan tak jarang nafsu hewani lebih mendominasi imajinasi dan apresiasi seks seseorang. Ingat kasus pelecehan dan permainan seks bebas yang terjadi dalam beberapa kasus di Jakarta sebagaimana diungkapkan penulis Jakarta Undercover, Sex 'n the City, Moammar Emka (2003). Dalam kenyataannya, menurut Emka, pesta seks illegal di Jakarta telah menjadi menu harian kalangan jetset, seperti pesta seks Nude Party, underground party di basement, Service Dobel-Tripel Vip Sauna, Seks Bulan Madu Pajero Goyang, Seks Sandwitch Sashimi Gerls, Nude Ladies Nite VIP Casino dan berbagai jenis pesta seks lainnya. ${ }^{6}$

Di kalangan seniman tertentu, dengan alasan seni, seksualitas malah sudah menjadi kebutuhan sehari-hari yang wajar dan sudah biasa, yang mendukung etos kerjanya, seperti kebutuhan makan dan minum. Bahkan pada akhirnya seksualitas itu menjadi pembangkit energi kerja (energizer) dan inspirasi kreativitas kebersenian seseorang. Pada gilirannya, bagi kalangan seniman liberal, misalnya, seks akhirnya dijadikan legitimasi untuk memompa kreativitas keberkeseniannya.

Karena itu, untuk membuktikannya dibutuhkan berbagai eksperimentasiekperimentasi seks. Walhasil seks dianggap sesuatu yang tidak lagi ditabukan, dirahasiakan, atau disakralkan. Di sinilah terjadinya desakralisasi terhadap aktivitas seksual. Maka kemudian yang berlaku adalah prinsip Machiavelli, "segala cara dikapai" untuk mengagungkan seksualitas. Atas dasar itulah maka seksualitas, apa pun bentuknya,

${ }^{5}$ Lihat buku Kegelisahan Seorang Feminis, Sosok Virginia Woolf (1989). Jakarta : Grafiti.

${ }^{6}$ Baca, "seks Undercover : Ikon Bokong Inul" dalam BASIS, No. 03-04 Th ke-52, Maret-April 2003. 
akan sah-sah saja dilihat dari kacamata seni, dengan alasan demi ekspresi seni dan aktualisasi diri dalam berkesenian. Memang, pada dasarnya seks adalah sifat qudrati manusia yang sesuai dengan sunnatullah. Artinya, manusia diciptakan Tuhan laki-laki dan perempuan untuk saling kenal-mengenal satu dengan lainnya. Salah satu dari hasil perkenalan itu adalah diijinkannya manusia saling berhubungan seksual, setelah melewati proses dan aturan hukum (rule of law), berupa lembaga pernikahan. Akan tetapi manakala aktivitas seksual telah disalahmaknakan fungsi dan nilainya, dengan tatacara yang menyimpang dan melanggar tatasusila dan hukum agama, maka ia telah menodai nilai qodrati manusiawi, bahkan nilai manusia itu akan jatuh ke dalam alam hewani.

Fenomena yang terjadi di Jakarta di atas, dalam kaca mata Islam sebenarnya merupakan representasi pelampiasan dan permainan hasrat seks kaum free-sex yang jatuh ke dalam alam hewani tersebut. Seks dalam potret masyarakat di atas hanyalah bertujuan melampiaskan nafsu syahwat (birahi) dan bahkan nafsu kebinatangan manusia. Jauh berbeda dengan paradigma kaum liberalis yang menganut kebebasan seks, seksualitas dalam Islam memiliki tujuan dan fungsi yang sangat agung, sakral, bermartabat, dan bernilai futuristik-eskatologis. Kongkretnya, aktivitas seksual dalam Islam tidaklah boleh dijadikan media iseng-iseng (exercise) bagi pacaran bebas kaum muda-mudi, seperti yang terjadi dewasa ini. Oleh karena itu, untuk menjaga nilai kesucian seks, Islam melarang keras pergaulan bebas, pacaran bebas, yang hanya mengumbar nafsu sayahwat. Hal itu karena pacaran bebas kebanyakan anak muda sekarang telah melampaui batas-batas yang diharamkan syariat Islam, seperti berdua-duaan, berpelukan, berciuman, berpegangan tangan, atau bahkan berhubungan intim seperti yang seharusnya hanya boleh dilakukan oleh pasangan suami istri. Islam oleh karenanya mengkatagorikan pacaran sebagaimana tersebut di atas sebagai perbuatan zina, yang diharamkan agama. Padahal Allah SWT melarang keras perbuatan zina, Wa la taqrabuz-zina, innahu kana fahisah, "janganlah engkau dekati perbuatan zina, karena sesungguhnya zina itu adalah perbuatan keji” (QS.Al-Isra', $17: 32$ ).

Kalaulah anak muda-mudi ingin berkenalan (ta'aruf), Islam mengajarkan etika berta'aruf yang halal, yang islami. Representasi pacaran yang islami ilustrasinya dapat 
dibaca dalam novel pesantren Ayat-ayat Cinta (2005) karya Habiburrahman El-Shirazy. Novel pesantren ini mengisahkan seorang pemuda Islam Fahri, seorang santri salaf metropolis dan musafir yang haus akan ilmu. Fahri sangat menjaga syariat Islam yang dianutnya. Bekal ilmu agamanya yang sangat dalam membuat novel ini memiliki kekuatan spiritual dan konseptual yang bergaya esoterik. Fahri kuliah di univesitas ternama Al Azhar University Cairo, Mesir. Sebagaimana remaja pada umumnya ia pandai bergaul dengan sesama dan lain jenisnya. Ia kebetulan hidup dalam sebuah apartemen yang bersebelahan flatnya dengan Maria, seorang perempuan Kristen koptik putri Madame Nahed. Keduanya, meski berbeda latar belakang budaya, bangsa dan agamanya mereka dapat menjalin cinta dan kasih sayang yang tulus, cinta antar anak manusia yang saling membutuhkan dan merasakan kemurnian cinta yang tulus, yang tidak dikotori nafsu birahi. Sungguh merupakan pertemuan dua hati yang damai, indah, dan syar'i dari dua latar belakang yang sarat dengan multikulturalisme. ${ }^{7}$

Atas dasar nilai kesucian yang sakral, seksualitas akan memiliki makna dan martabat kalau dilakukan dengan pintu gerbang pernikahan. Hubungan seks antara lakilaki dan perempuan dengan pintu pernikahan, bukan hanya akan mendapatkan kenikmatan dan ketenangan batin, tetapi juga akan berpahala dan bernilai ibadah. Karena itulah pernikahan memiliki fungsi sangat relegius dalam rumah tangga muslim. Dengan

\footnotetext{
${ }^{7}$ Bandingkan dengan novel Amerika The Color Purple (1983) karya Alice Walker. Dalam novel ini Celie sebagai tokoh utama adalah seorang perempuan Kristen yang hidup dalam lingkungan budaya Amerika. Ia adalah sosok wanita yang menjadi korban pelecehan seksual oleh ayah tirinya sendiri, justru di saat usianya masih 14 tahun. Setelah memiliki du orang anak yaitu Olivia dan Adam, ia dipaksa kawin oleh ayahnya dengan orang laki-laki yang sama sekali tak dicintainya. Tragisnya, ketika ia hidup dalam ikatan perkawinan pun, ia seringkali dilecehkan oleh suaminya dalam bentuk perkosaaan suami terhadap istri (marital rape) dan penganiayaan suami terhadap istri (wife abuse). Dalam keluarganya sendiri Celie mendapatkan kekerasan dalam rumah tangganya (KDRT).
}

Baca juga pelecehan seksual dalam novel Arab Imra'a 'Inda Nuqthat al-Shifr (1979) karya Nawal ElSadawi. Novel ini menampilkan tokoh Firdaus yang mengalami nasib sama dengan tokoh Celie dalam The Color Purple. Firdaus adalah seorang perempuan Muslim yang hidup di sebuah dusun di pedalaman Mesir yang sarat dengan kebudayaan Arab.Ia menjadi korban pelecehan seksual olehg pamannya sendiri, bahkan ketika ia masih usia kanak-kanak. Setelah tamat SMA Firdaus dipaksa pamannya untuk menikah dengan seorang manula (manusia lanjut usia), bernama Eyang Mahmud. Sebagaimana Celie, ketika masih dalam ikatan pernikahan itu, Firdaus seringkali mendapatkan pelecehhan seksual dari suaminya sendiri (marital rape) dan tindak penganiayaan suami terhadap istrinya (wife abuse). Dalam perjalanan hidupnya ia sering digoda dan dilecehkan laki-laki hingga ajalnya menjelang. Alangkah tragisnya kehidupan perempuan dalam kedua novel itu. 
pernikahan, hubungan seks antara suami-istri menjadi lebih bermartabat, elegan, dan berpahala karena merupakan bagaian dari ibadah kepada Allah SWT. Bukan hanya itu, nilai seksualitasnya di samping bernilai ibadah, seks pascanikah juga akan mendatangkan barakah berupa ketenangan hati (sakinah), ketentraman pikiran (khusu'), cinta dan kasih sayang (mawaddah wa rahmah), dan kesempurnaan beragama (khairuddin). Karena itulah, Nabi SAW dalam hadisnya mengatakan "Nikahkanlah seorang laki-laki yang sendirian, karena pernikahan akan menyempurnakan separoh dari agamanya". Sebagai contoh nilai ibadah yang didapatkan suami istri itu adalah aktivitas hubungan seks sebelum mencapai "puncak", Rasululah SAW bersabda dalam hadisnya yang diriwayatkan 'Aisyah RA,

"Barang siapa meremas tangan istrinya dan merayunya, Allah menulis baginya satu kebajikan dan menghapus satu keburukan dan mengangkat satu derajat untuknya. Dan ketika suami memeluknya, Allah menulis baginya sepuluh kebajikan, menghapus sepuluh keburukan, dan mengangkat sepuluh derajat untuknya. Dan ketika ia menciumnya, Allah menulis baginya dua puluh kebajikan, menghapus dua puluh keburukan, dan mengangkat dua puluh derajat baginya. Dan ketika ia menggaulinya, hal itu lebih baik daripa dunia dan segala isinya”.

Perlu ditandaskan di sini bahwa tujuan perkawinan dalam Islam bukanlah sematamata karena persoalan biologis (seks). Seksualitas hanyalah bagian kecil dari fungsi dan tujuan perkawinan dalam Islam, karena tujuan utama perkawinan adalah melangsungkan keturunan yang baik dan kuat (dzurriyatan thoyyibah), baik kuantitas maupun kualitasnya. Dalam konteks ini Allah mengkhawatirkan akan lahirnya generasi yang lemah, "Dan hendaklah takut kepada Allah orang-orang yang seandainya meninggalkan di belakang mereka (generasi) anak-anak yang lemah, yang mereka khawatir terhadap kesejahteraan mereka....."(QS An-Nisa', 4 : 9). Jadi, seksualitas bukanlah satu-satunya alasan mengapa manusia harus mengikuti jalur institusi perkawinan. Karena tujuan dan fungi pernikahan dalam Islam, di samping untuk memenuhi kebutuhan seks, adalah untuk 
tujuan ibadah, mengikuti sunnah Nabi SAW, meneruskan keturunan yang baik (dzurriyatan thayyibah), mendapatkan ketenangan (sakinah) dan kebahagiaan (sa'adah) dalam berumah tangga, kasih sayang (mawaddah warahmah), menghindari maksiat (zinah) dan menyempurnakan keislaman seseorang . Berbeda dengan semangat gerakan kaum feminis radikal yang ingin membongkar institusi perkawinan karena dianggap membelenggu perempuan, Islam justru menjunjung tinggi pintu perkawinan yang sah demi menjaga martabat kemanusiaan dan demi menempatkan keberadilan antara laki-laki dan perempuan dalam konteks seksual.

Sebagai konsekuensi logis dari syahadah seorang muslim adalah kesanggupannya untuk menjalankan perintah agamanya secara totalitas Islam, tidak sepotong-sepotong. Ini sesuai dengan perintah Allah dalam QS Al-Baqarah, 2 : 208, "Ya ayyuhallazina amanu udkhulu fissilmi kaffah...." (Wahai orang-orang yang beriman, masuklah kamu ke dalam agama Islam secara keseluruhan (totalitas) ....”. Makna dari totalitas Islam itu mencakup seluruh aspek kehidupan muslim, dalam ibadah, bekerja, berdagang, bermuamalah, termasuk urusan berumahtangga, khususnya dalam hal berhubungan seksual antara suami-istri. Oleh karena itu, Islam mengajarkan bagaimana tata cara hubungan seks yang Islami, sesuai tuntunan ajaran Quran dan Sunnah Nabi SAW.

Hubungan seksual antara suami istri yang Islami dapat dimulai dari memilih waktu yang tepat dan tempat yang bersih. Suami istri sebelum memasuki kamar tidur, sebaiknya mensucikan diri lebih dahulu, mandi besar dan mengambil air wudhu, agar badan segar dan bau keringat hilang. Setelah itu hendaklah mengenakan pakaian yang indah, bersih dan wewangian yang berbau harum semerbak yang disukai istrinya, karenanya membawa suasana indah, bergairah, dan harum mawangi. Begitu pula istri yang solikhah hendaknya sudah siap dengan dengan segala pakaian yang indah, bersolek yang cantik, dan memakai parfum yang harum baunya, yang mempu menggoncangkan gairah suami.

Mulaliah sang suami memasuki kamar istrinya dengan mendahulukan kaki kanannya sambil menyampaikan salam lembutnya, "Bismilahi wasalamu 'ala Rasulillah Assalamu'alaikum...ya habibi" (Dengan menyebut asma Allah, semoga kesejahteraan 
tetap enantiasa terlimpahkan kepada Rasulullah, semoga keselamatan selalu dilimpahkan Allah kepadamu). Kemudian suami istri salat sunnah berjamaah dua raka'at untuk mendapatkan ketenangan dan rahmat-Nya. Selesai salat keduanya membaca surat AlFatihah, Al-Ikhlas, Al-Falaq, An-Nas, dan salawat Nabi tiga kali, dilanjutkan memanjatkan doa kepada Asllah agar rumah tangganya sakinah, barakah, bahagia dunia akhirat dan mendapat keturunan yang salih dan salihah. Kemudian suami memegang kening istrinya sambil berdoa "Allahumma inni as aluka khairaha wa khaikra ma jabalta 'alaiha wa a'udzubika min sarriha wa sarri ma jabalta 'alaiha” ( Ya Allah saya mohon kepada-Mu dari kebaikan wanita ini dan kebaikan-kebaikan yang sudah Kau tanamkan pada dirinya, dan aku berlindung kepada-Mu dari keburukan-keburukan yang sudah Kau tanamkan kepadanya). Lalu mulaiah suami menyampaikan ungkapan dan kata-kata yang halus, lemah lembut kepada istrinya untuk memulai "membuka pemanasan" awal. Sebelum sampai "menuju puncak", suami hendaknya mulai menggauli istrinya dengan pemanasan (warming up) terlebih dahulu. Hal inim penting dilakukan untuk merangsang gairah seks sang istri dan untuk menciptakan "irama permainan" yang harmonis. Pemanasan dapat dilakukan dengan bersendaugurau, bermesraan, berpelukan, saling membelai, berciuman, dan memberikan sentuhan yang merangsang istri. Nabi SAW melarang sahabat-sahabat yang berhubungan intim laksana binatang ternak, yaitu tanpa adanya masa perantara atau pemanasan lebih dahulu.

Sentuhan yang merangsang istri bisa dimulai dari bagian tubuh yang kurang sensitif, sensitif, dan pada puncaknya pada daerah yang paling sensitif. Menurut majalah Femina (1996) daerah sensitif yang bagus dirangsang itu adalah daerah erotis seperti daun telinga, mulut, paha bagian dalam, puting payudara, pantat dan bagian belakang telinga. Karena itu suami bisa memulai dengan meraba tangan istrinya, meremasnya dengan penuh cinta dan kasih sayang. Atau bisa mulai dengan ciuman pada pipi, kening, belakang telinga, leher, perut, payudara, pada bagian puting payudara, dan sekujur tubuhnya. Betapa indah dan bahagia suami istri yang dapat mesra dalam babak "pemanasan" ini, karena selain dapat kenikmatan juga mereka mendapat pahala. Oleh karena itu Rasululah SAW bersabda dalam hadisnya yang diriwayatkan 'Aisyah RA, "Barang siapa meremas tangan istrinya dan merayunya, Allah menulis baginya satu 
kebajikan dan menghapus satu keburukan dan mengangkat satu derajat untuknya. Dan ketika suami memeluknya, Allah menulis baginya sepuluh kebajikan, menghapus sepuluh keburukan, dan mengangkat sepuluh derajat untuknya. Dan ketika ia menciumnya, Allah menulis baginya dua puluh kebajikan, menghapus dua puluh keburukan, dan mengangkat dua puluh derajat baginya. Dan ketika ia menggaulinya, hal itu lebih baik daripa dunia dan segala isinya". Begitu besarnya pahala ibadah suami istri dalam masalah hubungan intim, maka dalam kitab 'Uqudulujain disebutkan, sekali-kali istri dilarang menolak ajakan suaminya jika suami bermaksud ingin menggaulinya.

Hadis Nabi SAW mengatakan “Apabila seorang laki-laki mengajak istrinya untuk melayani dirinya di tempat tidur, lalu istrinya tidak mau melayaninya, niscaya para malaikat akan melaknat perempuan tersebut sampai tiba waktu subuh”. Dalam hadis Nabi SAW yang lain dikatakan, “Ada seorang perempuan mendatangi Nabi dan berkata, “ Ya Rasulallah, apakah hak seorang suami yang harus dipenuhi oleh istrinya?. Nabi SAW menjawab, "Hendaklah seorang istri tidak enggan dirinya melayani suami, walaupun ia berada di atas punggung seekor unta (berada dalam perjalanan).” (lihat, Qurratul 'Uyun, hal.104).

Dalam hal tata cara berhubungan intim antara suami istri di kamar, pasangan suami istri disarankan agar melepaskan semua pakaiannya, tetapi dalam "ketelanjangannya" mereka harus tetap dalam satu selimut, tidak terbuka tanpa satu pun penutup tubuh. Nabi SAW bersabda, "Apabila salah satu di antara kalian bersetubuh, maka jangalah melakukannya dengan cara keduanya telanjang bulat, seperti telanjang bulatnya dua ekor keledai. Dan hendalah kalian mengawalinya dengan cumbuan dan ciuman" (HR Ibn Majah). Setelah pemanasan selesai, dan jalan "menuju puncak" sudah tampak licin, maka permainan mesra ddan lembut, segeralah suami (dengan kesepakatan istri) memberikan "sendoknya" untuk "mangkok" sang istri sambil membaca doa, "Bismillahi, allahumma jannibnasy syaithanna, wa jannibisy syaitana ma razaqtana" (Dengan menyebut nama Allah, Ya Allah jauhkan kami dari godaan setan, dan jauhkanlah setan dari sesuatu yang akan Kau anugerahkan kepada kami) (HR Bukhari). 
Dalam hubungan ini Al-Ghazali berpendapat, "Disunahkan bagi orang yang akan melakukan persetubuhan agar memulai dengan membaca basmallah, surat Al-Ikhlas, dan membaca doa, "Bismillahil 'aliyil 'adzim, Allahummaj'alha dzurriyatan thayyiban inkunta qaddarta an takhruja dzalika min syulbi”, Dengan nama Allah yang Maha Tinggi dan Maha Agung. Ya Allah jadikanlah istriku sebagai lantaran terwujudnya keturunan yang baik, bila Engkau menentukan keterunan itu memancar dari ruas tulang sulbiku”. Di sinilah klimaks making love itu berlangsung dengan kekompakan antara suami dan istri untuk bisa menikmati indahnya "menuju puncak" bersama-sama. Dalam kitab Qurratul 'Uyun karya Syekh Abi Muhammad Maulana At-Tahami, hendaklah suami bisa menjaga dan menahan perasaan orgasme, sampai istri dapat merasakan kebersamaan berada di "titik puncak". Saat ejakulasi tiba, sang suami disunnahkan membaca doa (dalam hatinya), "Alhamdulillahilladzi khalaqa minal ma-i basyaran faja'alahu nasaban wa sihra, wa kana rabbuka qadira” (Segala puji bagi Allah, yang menciptakan manusia dari mani, dan dijadikan-Nya dengannya keturunan dan keluarga. Sesungguhnya Dia-lah Tuhanmu yang Maha Kuasa).

Dalam suasana "puncak" itulah suami dilarang melepaskan "kerisnya" sebelum sampai tiba ejakulasi, karena kenikmatan itulah ang ditunggu-tunggu setiap istri dalam berhubungan. Karena itu Nabi SAW mengatakan dalam hadisnya dalam Kitab Qurratul 'Uyun, "Berusahalah kalian menyenangkan istri-istrimu, sebab senangnya para istri itu ada pada (kenikmatan) kemaluan (vagina) mereka ketika disetubuhi suaminya”.

Mengenai waktu yang baik untuk berhubungan intim antara suami istri, penulis Qurratul'Uyun menyarankan agar pasangan suami istri menghindari tanggal 12 Muharram, 10 safar, 4 Rabbiul Awwal, 18 Jumadil Ula, 12 Rajab, 26 Sya'ban, 2 Syawal, 18 Zulkaidah, dan 8 Zulhijjah, baik untuk acara pernikahan maupun untuk berjima'. Sebaliknya, disarankan waktu yang lebih baik untuk berjima' adalah malam Kamis dan malam Jumat. Sedang waktu yang tepat untuk berhubungan adalah setelah shalat 'Isya atau pada permulaan malam.

Dalam hal "bumbu penyedap" seks, memang tidak dapat dipungkiri bahwa ada sebagian orang dari kalangan pesantren yang membaca wirid-wirid tertentu sekedar untuk 
menambah gairah dan kenikmatan seksnya atau untuk pengasihan. Wirid-wirid itu diamalkan untuk menambah "madu-kekuatan" seksualnya, khususnya bagi pihak lakilaki. Jadi, untuk masalah bumbu dalam hubungan seksual pun, Islam mengajarkan kesantunan dengan tetap menjaga etika, kesehatan, dan sunnatullah atas penciptaan manusia. Dalam hubungan ini, dalam tradisi pesantren tidak secara eksplisit diajarkan cara-cara untuk menambah gairah seks dengan obat-obatan aditif, jamu kuat, atau datang kepada dukun, seperti Mak Erot, Nyi Fatimah, atau tempat lainnya. Hal ini di samping karena untuk menjaga kesehatan natural yang sudah ditaqdirkan kepada manusia, akan tetapi juga agar tidak terjerumus dalam jalan kesesatan dan kemusyrikan.

Salah satu rujukan wifiq dan rajah dalam tradisi pesantren adalah Kitab Manba' Usul Al-Hikmah Lil Buni (tanpa tahun) karya Imam Abul Abbas Ahmad bin Ali Al-Buni. Dalam kitab ini di antaranya diterangkan makna dan fungsi huruf-huruf mukhata'ah (huruf yang terpotongpotong). Disebutkan pula asmaul a'dzam (nama-nama Allah yang Agung) yang biasanya menggunakan Bahasa Suryani, adakalanya menggunakan Bahasa Arab yang berguna untuk wifik. Misalnya asmaul a'dzam 'Ya Hu', 'Yayuhin' 'Namuhin', 'asaliya', Naja'aliyan' dan 'Sasalat'.

Memang harus diakui bahwa banyak naskah kuno yang secara khusus mengulas masalah seni berseks, cara-cara mencapai kenikmatan seksual, dan ramuan-ramuan "kuku bima" untuk menambah "kejantanan" laki-laki. Di antaranya adalah buku seni bercinta dan seks dari Arab, Parfumed Garden "Taman Wewangian”, karya Syeikh Nefzawi. Buku itu mengekspos seni bercinta dan hubungan seks, gaya dan posisi berhubungan seks yang nikmat, serta variasi berhubungan seks yang membahagiakan suami-istri. Pada bagian belakang buku itu dipaparkan bagaimana membangun hubungan seks yang maksimal, memberikan resep dan ramuan jamu "Mak Erot"-nya Arab. Termasuk dalam hal ini bagaimana memperbesar alat vital laki-laki, bagaimana menyempitkan vagina perempuan, bagaimana menghilangkan bau ketek dan bau vagina, dan resep jamu untuk memperkuat dan memperlama "kekuatan" laki-laki. Sebagai contoh, dijelaskan dalam buku itu bahwa dengan ramuan minyak unta, madu, jahe, perasan bawang, dan puluhan kuning telor, seorang "raja" Arab dapat memerawani delapan puluh gadis dalam semalam, tanpa orgasme. Buku yang senada dengan itu juga terdapat dalam naskah kuno Buton, sebuah naskah saduran dari naskah Arab Kuno, yang berisi berbagai ramuan "jamu kuat laki-laki” (Lihat, Katalog Naskah Buton, 2003 dan Katalog Koleksi Naskah Ashari, 1998).

\section{Simpulan}


Dalam perjalanannya dewasa ini penelitian filologis terhadap naskah-naskah pesantren cukup mengalami perkembangan yang menggembirakan. Hal ini bisa dicermati dari beberapa upaya nyata yang dilakukan oleh beberapa lembaga pemerintah maupun oleh lembaga swadaya masyarakat (LSM). Melalui Lembaga Penelitian dan Pengembanan (Litbang) Kementrian Agama, khususnya bidang lektur keagamaan, pemerintah cukup memberikan ruang dan kesempatan bagi para peneliti untuk mengkaji dan mengadakan penelitian dalam dunia pernaskahan Nusantara. Di samping itu, penelitian filologis Nusantara juga tampak menggairahkan dengan kiprahnya lembaga semacam Masyarakat Pernaskahan Nusantara (Manassa), yang dalam beberapa kesempatan telah menjalin kerjasama dengan Lektur Keagamaan Litbang Kementerian Agama. Dalam dunia akademik, kajian filologis terhadap naskah-naskah Nusantara memang telah banyak dilakukan oleh beberapa perguraun tinggi yang memiliki peminatan dalam studi filologi seperti di UI, UGM, UNDIP, UNPAD, dan lainnya. Namun demikian, perkembangan terakhir kajian filologi juga merambah dan menguat di UIN dan IAIN, seperti di UIN Jakarta, UIN Jogjakarta, IAIN Walisongo Semarang dan lainnya. Melihat perkembangan itu, maka prospek penelitian filologi pesantren di Nusantara semakin membangkitkan optimisme baru. Khususnya untuk kaian naskah-naskah sastra kitab dan naskah presantren lainnya. Wallahu a'lam.

\section{Daftar Pustaka}

Abdullah, Muhammad, 1992. Kesenian Blantenan : Kesenian Tradisional Dalam

Tradisi Pesantren di Kaliwungu Kendal. Semarang : Laporan Penelitian Lemlit UNDIP. 
Abdurrahman As-Suyuti, Jalaluddin, th Ar-Rahmah Fiththib wal Hikmah.

Ahmad, Abul Abbas, bin Ali Al-Buni, th Mamba'u Ushulul Hikmah.

Al-Ghazali, th Al-Munqid Minadzdzalal , (tanpa tahun). Al-Aufaq.

Al-Muthawwi, Jasim Muhammad. 2007. Hidup Sesudah Mati. Solo : Pustaka

$$
\text { Arafah. }
$$

Azam, Abdullah, 1985. Ayatu Ar-Rahman Fi Jihad Al-Afghan. Kuala Lumpur :

Mathb'ah Kazhim Dubai UEA.

Basuki, Anhari, 1988. "Sastra Pesantren” dalam Lembaran Sastra. Semarang :

Fakultas Sastra UNDIP.

Hawwa, Said, 1996. Jalan Ruhani. Bandung : Mizan.

Mundzir, Muhammad Nadzir, (tanpa th). Singir Tajwij: Tanwiru 'l-Qari'. Surabaya :

Al-Ashriyah.

Muzakka, Moh. 1994. "Singiran : Sebuah Tradidsi Sastra Pesantren" dalam

Hayam Wuruk No. 2 Th. IX.

Padmosoekotjo, S. 1960. Ngengrengan Kasusastraan Djawa. Yogyakarta :

Hien Hoo sing.

Qurdi, Imam, (tanpa tahun). Tanwirul Qulub.

Singir Paras Nabi. (tanpa th). Surabaya : Maktabah Said bin Nubhan wa Auladihi.

Soewignyo, R. Poerwo dan R. Wirawangsa. 1920. Pratelan Kawontenaning Boekoe-boekoe Basa Djawi Tjitakaningkan Kasimpen Wonten ing Gedong Boekoe (Museum) ing Pasimpenan Bibliotheek XXXIII. Drukkerij Ruygrik and Co.

Sibawaihi, 2004. Eskatologi Al-Ghazali dan Fazlur Rahman : Studi Komparatif Epistemologi Klasik-Kontemporer. Yogyakarta : Penerbit Islamika.

Siraj, (anpa tahun). Syi'ir Erang-erang Sekar Panjang.

Teeuw, A. 1984. Sastra dan Ilmu sastra : Pengantar Teori Sastra. Jakarta : Pustaka

Jaya.

Tim IAIN, 1993. Ensiklopedi Islam. Jakarta : PT Ichtiar Baru van Hoeve. 
Thohir, Mudjahirin, 1997. Inventarisasi Sastra Pesantren di Kaliwungu Kendal.

Semarang : Laporan Hasil Penelitian Lemlit UNDIP. 